\title{
PET and SPECT Imaging of Tumor Angiogenesis
}

\author{
Marcian E. Van Dort ${ }^{1}, 3$, Pedram Navid-Azarbaijani², \\ Rajesh Ranga2 ${ }^{2}$ Alnawaz Rehemtulla2,3, Brian D Ross 1,3 , \\ Allan E David ${ }^{4}$ and Mahaveer S Bhojani ${ }^{1,3}$ \\ ${ }^{1}$ Dept. of Radiology, \\ ${ }^{2}$ Dept. of Radiation Oncology, \\ ${ }^{3}$ Center for Molecular Imaging, \\ University of Michigan Medical School, Ann Arbor, \\ ${ }^{4}$ College of Pharmacy, \\ USA
}

\section{Introduction}

\subsection{PET and SPECT imaging}

Positron Emission Tomography (PET) and Single Photon Emission Computed Tomography (SPECT) based functional imaging utilize radiolabeled tracers to provide information for real time visualization of physiological or biological processes in live animals or humans. Disease-related biomarkers involved in initiation and/or progression of a pathological condition are imaged by these nuclear imaging technologies which lead to early detection of abnormalities prior to the appearance of morphological changes visualized by other imaging modalities such as CT or MRI (1-3). Additional advantages of nuclear imaging approaches are high sensitivity of detection and high spatial resolution. Further they are either non- or minimally invasive and highly quantitative (4). Together, these characteristics of PET and SPECT make them an invaluable technique for monitoring some diseases and disorders.

There are significant differences between PET and SPECT, some of which are highlighted below. A major advantage of PET over SPECT is its 2-3 orders of magnitude greater sensitivity and quantitative capability (5). PET utilizes radioisotopes that decay via emission of positrons, whereas, SPECT radioisotopes decay by electron capture and/or gamma emission (5). Table 1 lists some of the most commonly used PET and SPECT radioisotopes and their physical properties. The synthetic chemistry behind development of these radioisotopes as tracers for imaging is dependent on the half-lives. For example, the short decay half-lives $(2-20 \mathrm{~min})$ of the PET radioisotopes: carbon-11, nitrogen-13 and oxygen-15 requires that radiotracer synthesis with these radioisotopes be conducted in close proximity to a cyclotron (3-5). On the other hand, radioisotopes such as fluorine-18, copper-64, indium-111, iodine-123 and iodine124 are sufficiently long-lived to allow transportation from regional commercial sites (3-5). Additionally, the radioisotopes gallium-68, copper-62 and technetium- $99 \mathrm{~m}$ can be conveniently obtained from an in-house generator (3-5). At the present time, clinical SPECT 
imaging is more prevalent than PET imaging due to both its cost effectiveness and the greater availability of SPECT scanners at most nuclear medicine clinics.

\begin{tabular}{|c|c|c|c|c|}
\hline Isotope & Imaging Mode & $\begin{array}{l}\text { Production } \\
\text { Method }\end{array}$ & Half-Life & Decay Mode(s) \\
\hline${ }^{11} \mathrm{C}$ & PET & Cyclotron & $20.4 \mathrm{~min}$ & $\beta+(99+\%)$ \\
\hline${ }^{13} \mathrm{~N}$ & PET & Cyclotron & $10 \mathrm{~min}$ & $\beta+(100 \%)$ \\
\hline $15 \mathrm{O}$ & PET & Cyclotron & $2.03 \mathrm{~min}$ & $\beta+(99.9 \%)$ \\
\hline${ }^{18} \mathrm{~F}$ & PET & Cyclotron & $110 \mathrm{~min}$ & $\begin{array}{l}\beta+(97 \%) \\
\text { EC }(3 \%)\end{array}$ \\
\hline 124I & PET & Accelerator & 4.2 days & $\begin{array}{l}\text { EC }(74.4 \%) \\
\beta+(25.6 \%)\end{array}$ \\
\hline $68 \mathrm{Ga}$ & PET & Generator & $68.3 \mathrm{~min}$ & $\begin{array}{l}\beta+(90 \%) \\
\text { EC }(10 \%)\end{array}$ \\
\hline${ }^{62} \mathrm{Cu}$ & PET & Generator & $9.73 \mathrm{~min}$ & $\begin{array}{l}\beta+(98 \%) \\
\text { EC }(2 \%)\end{array}$ \\
\hline${ }^{64} \mathrm{Cu}$ & PET & Reactor & 12.7 hours & $\begin{array}{l}\beta+(61 \%) \\
\beta-(39 \%)\end{array}$ \\
\hline $99 \mathrm{mTc}$ & SPECT & Generator & 6.02 hours & IC (100\%) \\
\hline 111In & $\begin{array}{l}\text { Gamma } \\
\text { Scintigraphy }\end{array}$ & Accelerator & 2.8 days & EC (100\%) \\
\hline $123 I$ & SPECT & Accelerator & 13.3 hours & $\beta+(100 \%)$ \\
\hline${ }^{192} \mathrm{Ir}$ & SPECT & Reactor & 73.8 days & $\begin{array}{l}\text { EC }(4.9 \%) \\
\beta-(95.1 \%)\end{array}$ \\
\hline${ }^{201} \mathrm{Tl}$ & SPECT & Cyclotron & 73 hours & EC $(100 \%)$ \\
\hline $82 \mathrm{Rb}$ & PET & Generator & $1.27 \mathrm{~min}$ & $\beta+(100 \%)$ \\
\hline $89 \mathrm{Zr}$ & PET & Cyclotron & 3.3 days & $\beta+(100 \%)$ \\
\hline
\end{tabular}

$\beta+=$ positron emission; $E C=$ electron capture; $I C=$ isomeric conversion, $\beta-=$ electron emission

Table 1. Common PET and SPECT Radioisotopes

In recent years, an effort has been made to combine anatomical imaging modalities (such as CT and MRI) with molecular imaging modalities in order to capitalize on the strengths of both techniques. These multi-modality approaches can provide both high structural detail and high detection sensitivity of pathophysiological changes giving greater insight into the dynamic processes of tumor growth and progression. Advances in this field have already been made and PET-CT technology is now available for use in many clinics (6-8). Further, the recent approval by the US Food and Drug Administration (FDA) of the first PET-MRI machine for clinical imaging (9) is a major step forward in multimodal imaging. Compared with PET-CT technology, PET-MRI scans demonstrate higher structural detail, especially of soft tissues, and additionally permit the use of MRI techniques such as perfusion imaging and MR spectroscopy (10). Furthermore, MRI scans (in PET-MRI) use magnetic fields instead of x-rays, thereby decreasing patient radiation doses in comparison to PET-CT scans 
(10). Boss et al. showed the effectiveness and reliability of PET-MRI in scanning intracranial tumors using $\left[{ }^{11} \mathrm{C}\right]$ methionine or $\left[{ }^{68} \mathrm{Ga}\right]$ DOTATOC (11).

The past decade has seen the investigation and validation of several radiotracers with particular emphasis in oncology. These targets include molecular biomarkers such as growth factor receptors, protein kinases, specific receptor over-expression or biological events such as angiogenesis, apoptosis, hypoxia and tumor proliferation (1-3). This review will highlight recent PET and SPECT radiotracer development for angiogenesis imaging with a major focus on their application in oncology.

\subsection{Biology of angiogenesis}

Angiogenesis, the formation of new blood vessels, plays a central role in growth of tumors beyond 1-2 $\mathrm{mm}^{3}$ as neovascularization is required to supply oxygen and nutrients and for removal of cellular wastes(12-14). Further, neo-angiogenesis is critical to the metastatic potential of tumors as it aids in the dispersion of cancer cells to distant organs. Recent advances in cellular and molecular biology have led to the identification of novel angiogenic biomarkers and molecular dissection of their signaling pathways $(13,15)$. One of the key signaling pathways involved in initiation of new tumor blood vessels is mediated by vascular endothelial growth factor (VEGF) and its receptor tyrosine kinase (VEGFR)(16-18). Pro-angiogenic signaling mediated by VEGF/VEGFR is critical when tumors outgrow their existing blood supply and frequently display oxygen deficiency (hypoxia). Hypoxia is known to trigger the secretion of VEGF (19-22). Binding of VEGF to its receptor initiates a signaling cascade that promotes the proliferation, migration and survival of endothelial cells, ultimately leading to angiogenesis (23-25). The angiogenic effects of the VEGF family are believed to be primarily mediated through VEGF-A. To date, VEGF-A (also referred to as VEGF) and its receptors are the most characterized signaling pathways in developmental and tumor angiogenesis(24, 26-35).

Alternative splicing of RNA has revealed the existence of at least nine different molecular isoforms for VEGF-A, comprising 121, 145, 148, 162, 165, 165b, 183, 189 or 206 amino acids(36-43). The angiogenic actions of VEGF-A are mediated primarily via two closely related endothelium-specific receptor tyrosine kinases (VEGFR-1 and VEGFR-2)(44-46). All of the VEGF-A isoforms bind to both VEGFR-1 and VEGFR-2, of which, VEGFR-2 is the major mediator of proliferation and angiogenesis (14). Thus, a variety of solid tumor cells overexpress VEGFR-2, which serves as poor prognostic marker for the survival of cancer patients $(47,48)$. Therefore, new therapies based on humanized monoclonal antibodies that inhibit VEGF-A are used to treat cancers of colorectal, lung, kidney and eye origin and there are many newer therapies under various stages of development $(27,49)$

\section{Molecular targets and ligands for PET/SPECT imaging of angiogenesis}

\subsection{VEGF receptor and ligands}

PET imaging of VEGFR expression in vivo was first demonstrated using VEGF 121 radiolabeled with ${ }^{64} \mathrm{Cu}$. Radiolabeling was achieved via ${ }^{64} \mathrm{Cu}$ chelation to a DOTA-VEGF ${ }_{121}$ conjugate (DOTA is an abbreviation for 1,4,7,10-tetraazacyclododecane- $N, N^{\prime}, N^{\prime \prime}, N^{\prime \prime \prime}$ tetraacetic acid). In vivo evaluation of ${ }^{64} \mathrm{Cu}$-DOTA-VEGF ${ }_{121}$ using microPET imaging of 
athymic nude mice bearing U87MG human glioblastoma xenografts showed rapid and high specific accumulation of the radioligand in small U87MG tumors (16\% injected dose per gram [ID/g]) at $4 \mathrm{~h}$ post-injection. Larger tumors showed significantly lower uptake $(1-3 \%$ ID/g). Differences in tumor localization between large and small tumors showed a good correlation with tumor VEGF receptor expression (VEGFR-2). In vivo VEGFR-2 specificity of the radioligand was also confirmed by pharmacological blocking experiments and ex vivo studies (immunofluorescence staining, western blot analysis). This study also demonstrated the dynamic nature of VEGFR signaling during tumor growth and proliferation. Subsequently, these authors also reported on the development of a ${ }^{64} \mathrm{Cu}$-labeled vasculature-targeting fusion toxin $\left(\mathrm{VEGF}_{121} / \mathrm{rGel}\right)$ composed of a $\mathrm{VEGF}_{121}$ linked recombinant plant toxin gelonin construct (rGel) for multimodality imaging and therapy of glioblastoma. Sustained tumor accumulation and high signal-to-noise ratios were demonstrated by this radioligand in mice bearing glioblastoma xenografts up to $48 \mathrm{~h}$ postinjection. Based on the pharmacokinetic information obtained from the imaging studies, therapeutic administration of $\mathrm{VEGF}_{121} / \mathrm{rGel}$ to mice bearing orthotopic U87MG glioblastomas revealed specific tumor neovasculature damage by histological analysis after a multiple dose treatment regimen.

Apart from their role in tumor angiogenesis, VEGF/VEGFR signaling plays a key role in other human pathologies. For example, myocardial infarction (MI) is known to activate VEGF/VEGFR signaling. PET imaging studies conducted in a rat model of MI with ${ }^{64} \mathrm{Cu}-$ DOTA-VEGF ${ }_{121}$ revealed a 3 - 4 higher myocardial uptake of radioactivity for up to 2 weeks following infarction as compared to controls $(50,51)$. In addition, PET imaging of VEGFR expression with ${ }^{64} \mathrm{Cu}$-DOTA-VEGF 121 in a rat stroke model showed peak tracer uptake in the stroke border zone at approximately 10 days post-surgery indicating neovascularization as confirmed by histopathology studies(52).

${ }^{111}$ In-labeled recombinant VEGF isoform VEGF 165 (111In-hn-Tf-VEGF) was reported by Chan and coworkers as a tumor angiogenic marker in experimental mice models. $\mathrm{VEGF}_{165}$ was fused through a flexible polypeptide linker to the $n$-lobe of human transferrin(53). The latter construct permitted labeling of the radioligand with 111In at a site remote from the VEGF receptor-binding domain. In radioligand stability studies, 111In-hn-Tf-VEGF demonstrated a moderate loss of ${ }^{111} \mathrm{In}$ to transferrin in human plasma in vitro over a $72 \mathrm{~h}$ period $(21.3 \% \pm$ $3.4 \%$ per day). Radioligand biodistribution studies and whole-body gamma camera imaging were conducted in athymic mice bearing subcutaneous U87MG human glioblastoma xenografts. ${ }^{111} \mathrm{In}-\mathrm{hn}-\mathrm{Tf}-\mathrm{VEGF}$ displayed tumor and blood radioactivity accumulations of 6.7 $\pm 1.1 \% \mathrm{ID} / \mathrm{g}$ and $1.6 \pm 0.4 \% \mathrm{ID} / \mathrm{g}$, respectively, at $72 \mathrm{~h}$ post-injection. Co-administration of a 100 -fold excess of VEGF led to a 15-fold decrease in tumor uptake of radioactivity. High uptake of radioactivity was also observed in liver $(45.5 \pm 7.5 \% \mathrm{ID} / \mathrm{g})$, kidneys $(39.4 \pm 7.0$ $\% \mathrm{ID} / \mathrm{g})$ and spleen $(35.6 \pm 4.4 \% \mathrm{ID} / \mathrm{g})$ at this time interval. The authors present evidence to indicate that uptake of radioactivity in these organs is due to ${ }^{111} \mathrm{In}-\mathrm{hn}-\mathrm{Tf}-\mathrm{VEGF}$ and not due to ${ }^{111}$ In-transferrin via transchelation of ${ }^{111}$ In from the radioligand to transferrin.

Along with labeling VEGF-A and its isoforms, efforts have also been made to create antiVEGF-A antibodies for imaging and therapeutic purposes. Success in this field was achieved with the creation of bevacizumab, a humanized monoclonal antibody that blocks VEGFinduced endothelial cell proliferation. A radiolabeled form of bevacizumab, ${ }^{89} \mathrm{Zr}$ - 
bevacizumab, was demonstrated to have high tumor uptake in small animal PET imaging $(54,55)$. A phase 1 clinical trial with ${ }^{124}$ I-labelled HuMV833 showed promising findings as well establishing the utility of radiolabeled antibodies in imaging $\operatorname{VEGF}(56,57)$.

\section{$2.2 \alpha_{v} \beta_{3}$ integrins and RGD peptide}

An indirect approach to angiogenesis imaging has focused on radioligands targeting the $\alpha_{v} \beta_{3}$ class of cell adhesion molecule integrins. Integrin $a_{v} \beta_{3}$ receptors are significantly upregulated in endothelial cells during angiogenesis but not in mature vessels or nonneoplastic epithelium (Brooks PC, Science 1994; Pasqualini R, Nat Biotechnol, 1997). Integrin $\mathrm{a}_{\mathrm{v}} \beta_{3}$ is also expressed in a variety of tumor cells, including melanoma, late-stage glioblastoma, ovarian, breast and prostate cancer. The ability to visualize and quantify integrin $\alpha_{v} \beta_{3}$ expression in vivo would allow for appropriate selection of patients for antiintegrin treatment and also monitor treatment efficacy in such patients.

Radioligand development for $\alpha_{v} \beta_{3}$ imaging has focused primarily on small RGD peptide antagonists. The tripeptide sequence motif, arginine-glycine-aspartate (RGD), is found in proteins of the extracellular matrix. Many integrins, including $a_{v} \beta_{3}$, link the intracellular cytoskeleton of cells with the extracellular matrix via recognition and binding to this RGD motif. [ $\left.{ }^{18} \mathrm{~F}\right]$ GalactoRGD was the first radiotracer used for successful PET imaging of tumor $\mathrm{a}_{\mathrm{v}} \beta_{3}$ expression in patients. Subsequently, a hydrophilic D-amino acid containing tetrapeptide analog was also developed which demonstrated improved pharmacokinetics and proteolytic stability. $W u$ and coworkers have reported on the enhanced $a_{v} \beta_{3}$ receptor binding characteristics of dimeric and multimeric RGD peptides over monomeric peptides which has been attributed to an increased local concentration of RGD domains at the receptor vicinity (polyvalency effect). Accordingly, several $\left[{ }^{18} \mathrm{~F}\right]-$ and $\left[{ }^{64} \mathrm{Cu}\right]$-labeled dimeric and tetrameric RGD peptide analogs have been recently synthesized and evaluated by this group for integrin-targeted imaging in lung, brain and breast cancer. As an example, microPET imaging studies with a dimeric RGD peptide coupled to 4 - $\left[{ }^{18} \mathrm{~F}\right]$ Fluorobenzoate $\left\{\left[{ }^{18} \mathrm{~F}\right]-\mathrm{FB}-\mathrm{E}[\mathrm{c}(\mathrm{RGDyK})] 2\right\}$ showed predominantly renal excretion and twice as much tumor uptake in the same animal model as the monomeric analog $\left[{ }^{18} \mathrm{~F}\right]-\mathrm{FB}-\mathrm{c}(\mathrm{RGDyK})$. Binding potentials derived from tracer kinetic modeling studies showed good correlation with tumor integrin expression levels as measured by SDS-PAGE/autoradiography in the six tumor models tested.

Recently, a disulfide-based cyclic RGD called iRGD (internalizing RGD) was reported that showed binding affinity to the $\alpha_{v} \beta_{3}$ integrin and neurophilin-1 (NRP-1) receptor and portrayed the ability to penetrate tumor tissue for both imaging and drug-delivery purposes(58). These characteristics of the peptide iRGD (CRGDKGPDC) are achieved through a sequence of steps. Initially, iRGD binds to the $a_{v} \beta_{3}$ integrins expressed on the endothelium of tumor cells through its RGD motif(59). Subsequently, the peptide is proteolytically cleaved producing a C-terminal RGDK/R sequence that both increases the peptide's affinity to NRP-1 and decreases its binding activity to $\alpha_{v} \beta_{3}$ due to the CendR motif(59). This newfound affinity to NRP-1 provides iRGD its tumor penetrating capabilities(60). Not surprizingly, iRGD has become a major target for in vivo imaging as it can both home to tumor cells and also be internalized making the peptide a more effective imaging agent compared with other RGD peptides. iRGD imaging has been achieved using 
optical fluorescent and MRI agents, but a nuclear imaging agent has yet to be developed for this promising peptide $(58,59)$.

\subsection{Matrix Metalloproteinases (MMP)}

Matrix metalloproteinases (MMP's), a family of zinc- and calcium-dependent endopeptidases, facilitate endothelial cell migration during angiogenesis via the enzymatic degradation of connective tissue(61). Within the family of MMP's, MMP-2 and MMP-9 have been most associated with tumor aggressiveness and metastatic potential(62). Consequently, several MMP-specific peptides as well as small-molecule inhibitors (MMPI's) have been radiolabeled with ${ }^{125} \mathrm{I},{ }^{123} \mathrm{I},{ }^{64} \mathrm{Cu}$, or ${ }^{18} \mathrm{~F}$ for PET or SPECT imaging of angiogenesis(63). For example, Koivunen et al. discovered that the decapeptide cyclo(Cys-Thr-His-Trp-Gly-PheThr-Leu-Cys)(CTT) selectively inhibited MMP-2 and MMP-9 thus suppressing the migration of endothelial and tumor cells $(63,64)$. Subsequent radiolabeling with ${ }^{64} \mathrm{Cu}$ and chelation to DOTA showed low tracer accumulation in tumors(63). Studies on other MMP imaging agents have shown similar results calling into question their utility for angiogenesis imaging due to their low tumor targeting capabilities, nonspecific activity in preclinical trials, and in vivo instability(62).

\subsection{Nucleolin and F3 peptide}

It is now commonly believed that different organs and tissues may have a distinct vasculature, and molecular profiling studies have revealed that this heterogeneity stems from expression of distinct functional biomarkers in endothelial cells and its milieu. Similarly, molecular dissections of tumor and tumor vasculature have revealed that the angiogenic network of blood vessels in tumor is unique both structurally and physiologically. Tumor vasculature expresses unique biomarkers that distinguish it from normal blood vessels and allow targeting of cargo of therapeutic or imaging agents (14).

Phage display peptide libraries contain peptide motifs that can home to the tumor vasculature and bind directly to the molecules expressed on tumor vessels $(65,66)$. Utilizing in vivo phage display technology, Ruoslahti's group identified F3 peptide (KDEPQRRSARLSAKPAPPKPEPKPKKAPAKK) as a sequence that specifically binds to tumor and its angiogenic endothelial cells (67). Later studies identified Nucleolin, as the receptor for F3 peptide. Nucleolin is localized both within the nucleus and the cytoplasm and is involved in RNA transport and processing. However, in proliferating tumor cells, it is cyclically transported from the nucleus to cell surface and back by a specific shuttle mechanism (68). Subcellular distribution of fluorescently-labeled F3 peptide shadowed nucleolin localization both in vitro and in vivo (Figure 1, $(69,70))$. Further, we recently performed meta-analysis of microarray data from tumor samples and found that Nucleolin is upregulated in brain, head and neck and lung cancers when compared with respective normal tissue. Taken together, the overexpression of nucleolin and its unique localization at cell surface, suggest that nucleolin may be targeted for tumor imaging and delivery of therapeutic agents.

F3 peptide has been used to deliver fluorescent tags, siRNA, and therapeutic radionuclides to tumors $(44,71-75)$. We have recently demonstrated that this peptide sequence can carry a 
pay load of $80 \mathrm{~nm}$ multifunctional nanoparticles in a tumor specific manner (76) and that these reside at the tumor sites longer than the untargeted nanoparticles. Several groups have generated a variety of distinct F3-targeted nanoparticles and shown their efficacy in targeting mouse tumors or human xenografts in mouse $(44,71-75,77)$. We recently reported the development of an new F3 peptide with cysteine at the c-terminus. Fluorescently or [125I]-labeled conjugates of this peptide localized to tumors in a mouse model, when systemically administered (Figure 2).

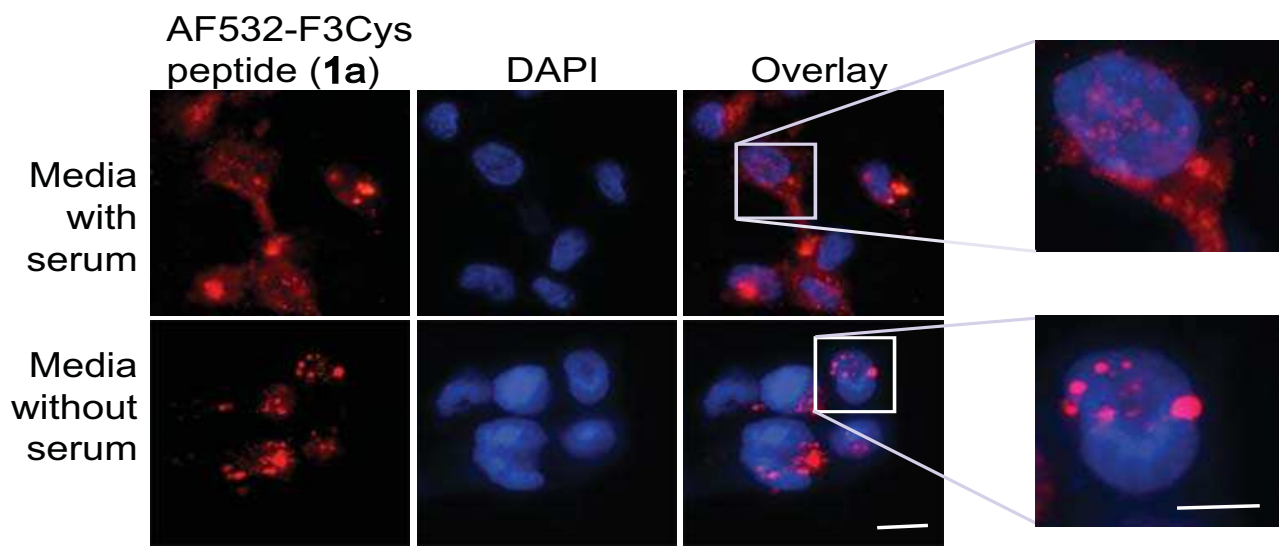

Fig. 1. Subcellular localization of Fluorescent-labeled F3Cys peptides shadows that of nucleolin. MDA-MB-435 cells, in optically clear bottom dishes, cultured in either serum free or serum containing media were stained with AF532-F3Cys, counterstained with DAPI and monitored under a fluorescent microscope. In cells grown in media containing 10\% serum, cell surface and nuclear staining of F3Cys was observed while serum starved cells showed predominantly nuclear staining without significant membrane staining. This suggests that F3Cys localizes to cell surface in actively growing cells. 


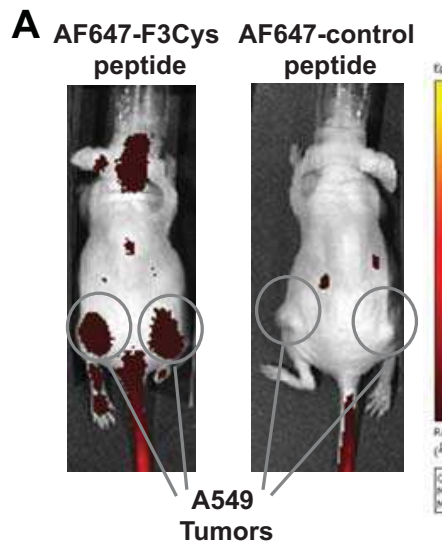

B
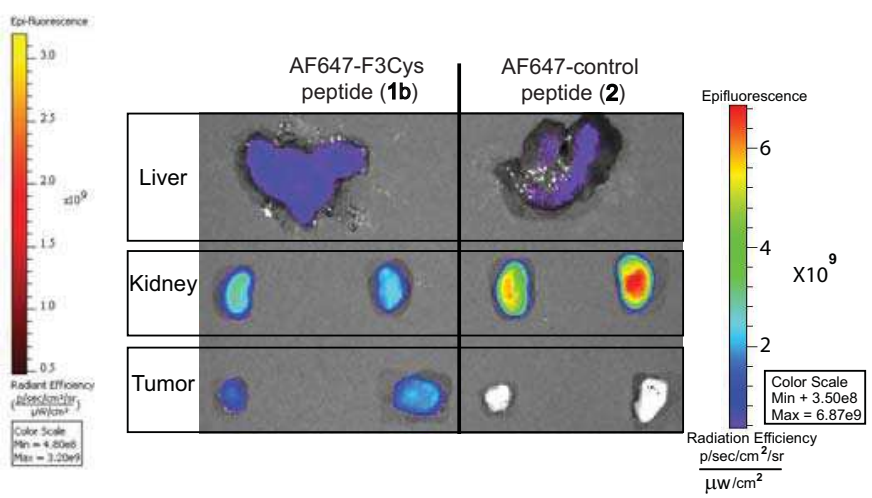

C

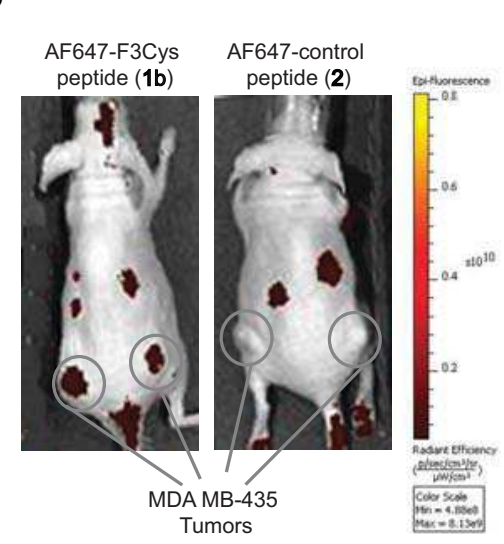

D

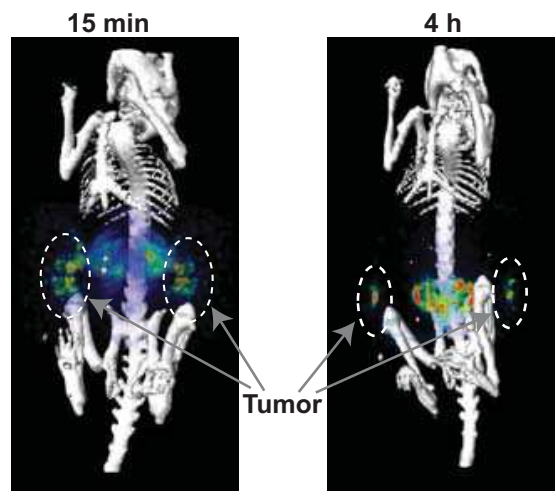

Fig. 2. Fluorescent or SPECT imaging using tagged F3-cys peptide. Mice bearing A549 (A) xenografts were injected i.v. via the tail vein with either AF647-F3Cys or AF647-Control peptide and fluorescence images were acquired over time. Tumor specific uptake at $2 \mathrm{~h}$ was observed only with AF647-F3Cys but not with AF647-Control peptide (A). Ex vivo fluorescence imaging of tumor, kidney and liver harvested $2 \mathrm{~h}$ after AF647-F3Cys peptide injection in animals bearing A549 Tumor xenografts show that F3 peptide is taken up by tumor, kidney and liver while AF647-Control peptide shows no tumor specific fluorescence (B). Tumor specific uptake was also seen with MDA-MB-435 (melanoma cancer cells) xenografts when AF647-F3Cys and not AF647-Control peptide was administered (C). SPECT imaging studies conducted following i.v. administration of [125I]IBMF3 to nude mice bearing MDA-MB-435 tumor xenografts showed distinct uptake of radioactivity in tumor as early as 15 min post-injection and also at $4 \mathrm{~h}$ post-injection (D). 


\subsection{Miscellaneous alternate targets}

Prostate-specific membrane antigen (PSMA) is expressed on the neovascular endothelium of a majority of solid type tumors and not on endothelial cells of normal tissue. Thus, radiolabelled PSMA may be utilized in the detection of tumor-specific angiogenesis(7880). For the detection of nodal metastasis in prostate cancer, the FDA approved ProstaScint, a PSMA antibody labeled with 111In (81, 82). Another 111In-labeled PSMA antibody (J591) in a phase I clinical trial was reported to accumulate in malignant sites of tumors associated with kidney, liver, colon, breast and melanomas suggesting a potential of PSMA in imaging angiogenesis(81-84).. In a preclinical study, a ${ }^{11} \mathrm{C}$-labeled small molecule ligand for prostate-specific antigen was shown to localize to prostate cancer in experimental animal models.

A number of extracellular matrix (ECM) proteins have also been targeted in the imaging of angiogenesis as some of the antigens in ECM have been discovered to be associated with neoangiogenic sites. Extra domain $\mathrm{B}$ of fibronectin and extra domain $\mathrm{C}$ of tenascin have been targeted in preclinical model systems to detect neoangiogenesis in malignant sites (63, $85,86)$

\section{Clinical relevance of imaging angiogenesis}

Radiotracer imaging techniques such as PET and SPECT offer unique advantages for investigation of angiogenesis in patients at the molecular level by virtue of its high sensitivity and adequate spatial and temporal resolution. At the clinical level, such approaches could be useful for lesion detection, to select patients likely to respond to therapies directed at such targets, to confirm successful targeting and dose optimization as well as treatment monitoring. Additionally, nuclear imaging techniques could also aid in the development of new angiogenesis-targeted drugs and their validation. For example, PET imaging can provide rapid characterization of a drugs pharmacokinetics and pharmacodynamic behavior in both pre-clinical studies and clinical trials thereby improving the speed, efficiency and cost of drug development. Taken together, these exciting developments will likely play an important clinical role in the management of human malignancies.

\subsection{Future outlook on angiogenesis radiotracer design}

The past decade has seen major advances in the field of PET and SPECT radiotracer development for visualizing the molecular events associated with angiogenesis. A vast majority of these approaches have either focused on radiolabeled analogs of vascular endothelial growth factor (VEGF) or RGD small peptide antagonists of the $\alpha_{v} \beta_{3}$ class of cell adhesion molecule integrins. Despite these achievements, there is still a need for improvements in synthetic strategies for existing radiotracers and the development of alternate radiotracers for angiogenesis imaging. For example, approaches using radiolabeled VEGF are complicated by several factors such as the presence of multiple VEGF isoforms, high renal expression of VEGF receptors and the mitogenic activity of VEGF. Additionally, clinical trials conducted with RGD-based radiotracers have shown wide heterogeneity in tumor binding both within the same patient and between patients (87). Furthermore, RGD 
peptides may have limitations for tumor imaging due to the limited number of $a_{v} \beta_{3}$ integrin receptors available per tumor cell and their low binding affinity (87). Thus, new radiotracers with improved targeting efficacy and pharmacokinetics are indispensible for successful clinical translation.

Angiogenesis is involved in a multitude of biological processes including, embryogenesis, female reproductive cycle, tissue remodeling and wound healing (88). Furthermore, imbalances or upregulation of angiogenic processes are observed in numerous disorders including rheumatoid arthritis, psoriasis, cardiac restenosis and diabetic retinopathy. Accordingly, the future availability of clinically-validated angiogenesis imaging radiotracers could have broad applicability in disease management beyond that of oncology.

\section{Summary}

In this review, we have focused on recent developments in the design of new PET and SPECT radiotracers for imaging the tumor angiogenic process and their biological evaluation in pre-clinical animal models and initial clinical studies. Radiotracers based on VEGF and the cell adhesion molecule integrin $\alpha_{v} \beta_{3}$ currently form the major focus for imaging agent development. Additionally, alternate approaches that focus on radiolabeled matrix metalloproteinase and prostate specific membrane antigen (PSMA) inhibitors as well as the tumor-homing F3 peptide are described. Molecular imaging techniques such as PET and SPECT continue to play an increasingly important role in both disease diagnosis at the presymptomatic stage and the monitoring of its progression and response to therapeutic intervention. The future availability of improved imaging biomarkers for angiogenesis and appropriate animal models for their validation will be crucial for unraveling this complex process in health and disease and could lead to important advances in the treatment of cancer.

\section{Acknowledgment}

This work was supported by the following NIH research grants: P50CA093990 (BDR), PO1CA085878 (BDR), U24CA083099 (BDR), P50 CADE97248 (MSB), P50CA093990 (MSB) and CA136429 (MSB).

\section{References}

[1] Weber WA. Positron emission tomography as an imaging biomarker. J Clin Oncol 2006;24: 3282-92.

[2] Wu AM. Antibodies and antimatter: the resurgence of immuno-PET. J Nucl Med 2009;50: $2-5$.

[3] O'Connor JP, Jackson A, Asselin MC, Buckley DL, Parker GJ, Jayson GC. Quantitative imaging biomarkers in the clinical development of targeted therapeutics: current and future perspectives. Lancet Oncol 2008;9: 766-76.

[4] Brandon D, Alazraki A, Halkar RK, Alazraki NP. The role of single-photon emission computed tomography and SPECT/computed tomography in oncologic imaging. Semin Oncol 2011;38: 87-108.

[5] Rahmim A, Zaidi H. PET versus SPECT: strengths, limitations and challenges. Nucl Med Commun 2008;29: 193-207. 
[6] Kaufmann PA, Di Carli MF. Hybrid SPECT/CT and PET/CT imaging: the next step in noninvasive cardiac imaging. Semin Nucl Med 2009;39: 341-7.

[7] Di Carli MF. Hybrid imaging: integration of nuclear imaging and cardiac CT. Cardiol Clin 2009;27: 257-63, Table of Contents.

[8] Di Carli MF, Hachamovitch R. Hybrid PET/CT is greater than the sum of its parts. J Nucl Cardiol 2008;15: 118-22.

[9] PET-MRI F. http://www.fda.gov/NewsEvents/Newsroom/PressAnnouncements/ ucm258700.htm.

[10] Fatemi-Ardekani A, Samavati N, Tang J, Kamath MV. Advances in multimodality imaging through a hybrid PET/MRI system. Critical reviews in biomedical engineering 2009;37: 495-515.

[11] Boss A, Bisdas S, Kolb A, et al. Hybrid PET/MRI of intracranial masses: initial experiences and comparison to PET/CT. J Nucl Med;51: 1198-205.

[12] Folkman J. Angiogenesis in cancer, vascular, rheumatoid and other disease. Nature medicine 1995;1: 27-31.

[13] Zhu AX, Duda DG, Sahani DV, Jain RK. HCC and angiogenesis: possible targets and future directions. Nat Rev Clin Oncol 2011;8: 292-301.

[14] Carmeliet P, Jain RK. Angiogenesis in cancer and other diseases. Nature 2000;407: 249-57.

[15] Chi AS, Sorensen AG, Jain RK, Batchelor TT. Angiogenesis as a therapeutic target in malignant gliomas. Oncologist 2009;14: 621-36.

[16] Kadambi A, Mouta Carreira C, Yun CO, et al. Vascular endothelial growth factor (VEGF)-C differentially affects tumor vascular function and leukocyte recruitment: role of VEGF-receptor 2 and host VEGF-A. Cancer research 2001;61: 2404-8.

[17] Tsuzuki Y, Fukumura D, Oosthuyse B, Koike C, Carmeliet P, Jain RK. Vascular endothelial growth factor (VEGF) modulation by targeting hypoxia-inducible factor-1alpha--> hypoxia response element--> VEGF cascade differentially regulates vascular response and growth rate in tumors. Cancer research 2000;60: 6248-52.

[18] Duda DG, Batchelor TT, Willett CG, Jain RK. VEGF-targeted cancer therapy strategies: current progress, hurdles and future prospects. Trends Mol Med 2007;13: 223-30.

[19] Detmar M, Brown LF, Berse B, et al. Hypoxia regulates the expression of vascular permeability factor/vascular endothelial growth factor (VPF/VEGF) and its receptors in human skin. J Invest Dermatol 1997;108: 263-8.

[20] Enholm B, Paavonen K, Ristimaki A, et al. Comparison of VEGF, VEGF-B, VEGF-C and Ang-1 mRNA regulation by serum, growth factors, oncoproteins and hypoxia. Oncogene 1997;14: 2475-83.

[21] Gu JW, Adair TH. Hypoxia-induced expression of VEGF is reversible in myocardial vascular smooth muscle cells. Am J Physiol 1997;273: H628-33.

[22] Baek JH, Jang JE, Kang CM, Chung HY, Kim ND, Kim KW. Hypoxia-induced VEGF enhances tumor survivability via suppression of serum deprivation-induced apoptosis. Oncogene 2000;19: 4621-31.

[23] Soltau J, Drevs J. Mode of action and clinical impact of VEGF signaling inhibitors. Expert Rev Anticancer Ther 2009;9: 649-62.

[24] Selleck SB. Signaling from across the way: transactivation of VEGF receptors by HSPGs. Mol Cell 2006;22: 431-2.

[25] McMahon G. VEGF receptor signaling in tumor angiogenesis. Oncologist 2000;5 Suppl 1: 3-10.

[26] Bagri A, Kouros-Mehr H, Leong KG, Plowman GD. Use of anti-VEGF adjuvant therapy in cancer: challenges and rationale. Trends Mol Med 2010;16: 122-32. 
[27] Grothey A, Galanis E. Targeting angiogenesis: progress with anti-VEGF treatment with large molecules. Nat Rev Clin Oncol 2009;6: 507-18.

[28] Tortora G, Ciardiello F, Gasparini G. Combined targeting of EGFR-dependent and VEGF-dependent pathways: rationale, preclinical studies and clinical applications. Nat Clin Pract Oncol 2008;5: 521-30.

[29] Harper SJ, Bates DO. VEGF-A splicing: the key to anti-angiogenic therapeutics? Nature reviews 2008;8: 880-7.

[30] Ellis LM, Hicklin DJ. VEGF-targeted therapy: mechanisms of anti-tumour activity. Nature reviews 2008;8: 579-91.

[31] Schneider BP, Sledge GW, Jr. Drug insight: VEGF as a therapeutic target for breast cancer. Nat Clin Pract Oncol 2007;4: 181-9.

[32] Nagy JA, Dvorak AM, Dvorak HF. VEGF-A and the induction of pathological angiogenesis. Annu Rev Pathol 2007;2: 251-75.

[33] Olsson AK, Dimberg A, Kreuger J, Claesson-Welsh L. VEGF receptor signalling - in control of vascular function. Nat Rev Mol Cell Biol 2006;7: 359-71.

[34] Jain RK, Duda DG, Clark JW, Loeffler JS. Lessons from phase III clinical trials on antiVEGF therapy for cancer. Nat Clin Pract Oncol 2006;3: 24-40.

[35] Rosen LS. VEGF-targeted therapy: therapeutic potential and recent advances. Oncologist 2005;10: 382-91.

[36] Patil AS, Sable RB, Kothari RM. Occurrence, biochemical profile of vascular endothelial growth factor (VEGF) isoforms and their functions in endochondral ossification. J Cell Physiol 2011.

[37] Giacca M. Non-redundant functions of the protein isoforms arising from alternative splicing of the VEGF-A pre-mRNA. Transcr 2010;1: 149-53.

[38] Carter JG, Cherry J, Williams K, Turner S, Bates DO, Churchill AJ. Splicing factor polymorphisms, the control of VEGF isoforms and association with angiogenic eye disease. Curr Eye Res 2011;36: 328-35.

[39] Rennel ES, Varey AH, Churchill AJ, et al. VEGF(121)b, a new member of the $\operatorname{VEGF}(x x x) b$ family of VEGF-A splice isoforms, inhibits neovascularisation and tumour growth in vivo. Br J Cancer 2009;101: 1183-93.

[40] Varey AH, Rennel ES, Qiu Y, et al. VEGF 165 b, an antiangiogenic VEGF-A isoform, binds and inhibits bevacizumab treatment in experimental colorectal carcinoma: balance of pro- and antiangiogenic VEGF-A isoforms has implications for therapy. Br J Cancer 2008;98: 1366-79.

[41] Yukata K, Matsui Y, Goto T, Kubo T, Yasui N. Differential expression of VEGF isoforms and VEGF receptors in cartilaginous tumors. Anticancer Res 2005;25: 955-7.

[42] Hofstaetter JG, Saad FA, Samuel RE, Wunderlich L, Choi YH, Glimcher MJ. Differential expression of VEGF isoforms and receptors in knee joint menisci under systemic hypoxia. Biochem Biophys Res Commun 2004;324: 667-72.

[43] Park JE, Keller GA, Ferrara N. The vascular endothelial growth factor (VEGF) isoforms: differential deposition into the subepithelial extracellular matrix and bioactivity of extracellular matrix-bound VEGF. Mol Biol Cell 1993;4: 1317-26.

[44] Zhang Z, Neiva KG, Lingen MW, Ellis LM, Nor JE. VEGF-dependent tumor angiogenesis requires inverse and reciprocal regulation of VEGFR1 and VEGFR2. Cell Death Differ 2010;17: 499-512.

[45] Tam J, Duda DG, Perentes JY, Quadri RS, Fukumura D, Jain RK. Blockade of VEGFR2 and not VEGFR1 can limit diet-induced fat tissue expansion: role of local versus bone marrow-derived endothelial cells. PLoS One 2009;4: e4974. 
[46] Jinnin M, Medici D, Park L, et al. Suppressed NFAT-dependent VEGFR1 expression and constitutive VEGFR2 signaling in infantile hemangioma. Nature medicine 2008;14: 1236-46.

[47] Ferrara N. Vascular endothelial growth factor: basic science and clinical progress. Endocrine reviews 2004;25: 581-611.

[48] Rudlowski C, Pickart AK, Fuhljahn C, et al. Prognostic significance of vascular endothelial growth factor expression in ovarian cancer patients: a long-term followup. Int J Gynecol Cancer 2006;16 Suppl 1: 183-9.

[49] Fischer C, Mazzone M, Jonckx B, Carmeliet P. FLT1 and its ligands VEGFB and PIGF: drug targets for anti-angiogenic therapy? Nature reviews 2008;8: 942-56.

[50] Gambhir SS, Rodriguez-Porcel M, Cai WB, et al. Imaging of VEGF receptor in a rat myocardial infarction model using PET. Journal of Nuclear Medicine 2008;49: 667-73.

[51] Sinusas AJ, Dobrucki LW. PET and SPECT in cardiovascular molecular imaging. Nat Rev Cardiol 2010;7: 38-47.

[52] Chen XY, Cai WB, Guzman R, et al. Positron Emission Tomography Imaging of Poststroke Angiogenesis. Stroke 2009;40: 270-7.

[53] Chan C, Sandhu J, Guha A, et al. A human transferrin-vascular endothelial growth factor (hnTf-VEGF) fusion protein containing an integrated binding site for (111)In for imaging tumor angiogenesis. J Nucl Med 2005;46: 1745-52.

[54] Nagengast WB, de Korte MA, Oude Munnink TH, et al. 89Zr-bevacizumab PET of early antiangiogenic tumor response to treatment with HSP90 inhibitor NVP-AUY922. J Nucl Med;51: 761-7.

[55] Nagengast WB, de Vries EG, Hospers GA, et al. In vivo VEGF imaging with radiolabeled bevacizumab in a human ovarian tumor xenograft. J Nucl Med 2007;48: 1313-9.

[56] Jayson GC, Mulatero C, Ranson M, et al. Phase I investigation of recombinant antihuman vascular endothelial growth factor antibody in patients with advanced cancer. Eur J Cancer 2005;41: 555-63.

[57] Jayson GC, Zweit J, Jackson A, et al. Molecular imaging and biological evaluation of HuMV833 anti-VEGF antibody: implications for trial design of antiangiogenic antibodies. J Natl Cancer Inst 2002;94: 1484-93.

[58] Ye Y, Zhu L, Ma Y, Niu G, Chen X. Synthesis and evaluation of new iRGD peptide analogs for tumor optical imaging. Bioorg Med Chem Lett;21: 1146-50.

[59] Sugahara KN, Teesalu T, Karmali PP, et al. Tissue-penetrating delivery of compounds and nanoparticles into tumors. Cancer Cell 2009;16: 510-20.

[60] Sugahara KN, Teesalu T, Karmali PP, et al. Coadministration of a tumor-penetrating peptide enhances the efficacy of cancer drugs. Science;328: 1031-5.

[61] Josephs D, Spicer J, O'Doherty M. Molecular imaging in clinical trials. Targeted oncology 2009;4: 151-68.

[62] Haubner R, Beer AJ, Wang H, Chen X. Positron emission tomography tracers for imaging angiogenesis. Eur J Nucl Med Mol Imaging;37 Suppl 1: S86-103.

[63] Dijkgraaf I, Boerman OC. Radionuclide imaging of tumor angiogenesis. Cancer Biother Radiopharm 2009;24: 637-47.

[64] Koivunen E, Arap W, Valtanen H, et al. Tumor targeting with a selective gelatinase inhibitor. Nature biotechnology 1999;17: 768-74.

[65] Ruoslahti E. Vascular zip codes in angiogenesis and metastasis. Biochem Soc Trans 2004;32: 397-402.

[66] Ruoslahti E, Duza T, Zhang L. Vascular homing peptides with cell-penetrating properties. Current pharmaceutical design 2005;11: 3655-60. 
[67] Porkka K, Laakkonen P, Hoffman JA, Bernasconi M, Ruoslahti E. A fragment of the HMGN2 protein homes to the nuclei of tumor cells and tumor endothelial cells in vivo. Proc Natl Acad Sci U S A 2002;99: 7444-9.

[68] Srivastava M, Pollard HB. Molecular dissection of nucleolin's role in growth and cell proliferation: new insights. Faseb J 1999;13: 1911-22.

[69] Bhojani MS, Ranga R, Luker GD, Rehemtulla A, Ross BD, Van Dort ME. Synthesis and Investigation of a Radioiodinated F3 Peptide Analog as a SPECT Tumor Imaging Radioligand. PLoS One;6: e22418.

[70] Christian S, Pilch J, Akerman ME, Porkka K, Laakkonen P, Ruoslahti E. Nucleolin expressed at the cell surface is a marker of endothelial cells in angiogenic blood vessels. J Cell Biol 2003;163: 871-8.

[71] Hah HJ, Kim G, Lee YE, et al. Methylene Blue-Conjugated Hydrogel Nanoparticles and Tumor-Cell Targeted Photodynamic Therapy. Macromol Biosci 2010.

[72] Bhojani MS, Van Dort M, Rehemtulla A, Ross BD. Targeted Imaging and Therapy of Brain Cancer Using Theranostic Nanoparticles. Molecular pharmaceutics 2010.

[73] Park JH, von Maltzahn G, Zhang L, et al. Systematic surface engineering of magnetic nanoworms for in vivo tumor targeting. Small 2009;5: 694-700.

[74] Derfus AM, Chen AA, Min DH, Ruoslahti E, Bhatia SN. Targeted quantum dot conjugates for siRNA delivery. Bioconjug Chem 2007;18: 1391-6.

[75] Akerman ME, Chan WC, Laakkonen P, Bhatia SN, Ruoslahti E. Nanocrystal targeting in vivo. Proc Natl Acad Sci U S A 2002;99: 12617-21.

[76] Reddy GR, Bhojani MS, McConville P, et al. Vascular targeted nanoparticles for imaging and treatment of brain tumors. Clin Cancer Res 2006;12: 6677-86.

[77] Orringer DA, Koo YE, Chen T, et al. In vitro characterization of a targeted, dye-loaded nanodevice for intraoperative tumor delineation. Neurosurgery 2009;64: 965-71; discussion 71-2.

[78] Bander NH. Technology insight: monoclonal antibody imaging of prostate cancer. Nature clinical practice 2006;3: 216-25.

[79] Zuckier LS, DeNardo GL. Trials and tribulations: oncological antibody imaging comes to the fore. Semin Nucl Med 1997;27: 10-29.

[80] Mease RC, Dusich CL, Foss CA, et al. N-[N-[(S)-1,3-Dicarboxypropyl]carbamoyl]-4[18F]fluorobenzyl-L-cysteine, [18F]DCFBC: a new imaging probe for prostate cancer. Clin Cancer Res 2008;14: 3036-43.

[81] Yao D, Trabulsi EJ, Kostakoglu L, et al. The utility of monoclonal antibodies in the imaging of prostate cancer. Seminars in urologic oncology 2002;20: 211-8.

[82] Smith-Jones PM, Vallabahajosula S, Goldsmith SJ, et al. In vitro characterization of radiolabeled monoclonal antibodies specific for the extracellular domain of prostate-specific membrane antigen. Cancer research 2000;60: 5237-43.

[83] Chopra A. 123I-Labeled (S)-2-(3-((S)-1-carboxy-5-(4-iodobenzylamino)pentyl)ureido) pentanedoic acid. 2004.

[84] Chopra A. 123I-Labeled (S)-2-(3-((S)-1-carboxy-5-(3-(4-iodophenyl) ureido)pentyl) ureido)pentanedoic acid. 2004.

[85] Guttery DS, Shaw JA, Lloyd K, Pringle JH, Walker RA. Expression of tenascin-C and its isoforms in the breast. Cancer Metastasis Rev;29: 595-606.

[86] Stollman TH, Ruers TJ, Oyen WJ, Boerman OC. New targeted probes for radioimaging of angiogenesis. Methods (San Diego, Calif 2009;48: 188-92.

[87] Danen EH. Integrins: regulators of tissue function and cancer progression. Current pharmaceutical design 2005;11: 881-91.

[88] Carmeliet P. Angiogenesis in health and disease. Nature medicine 2003;9: 653-60. 


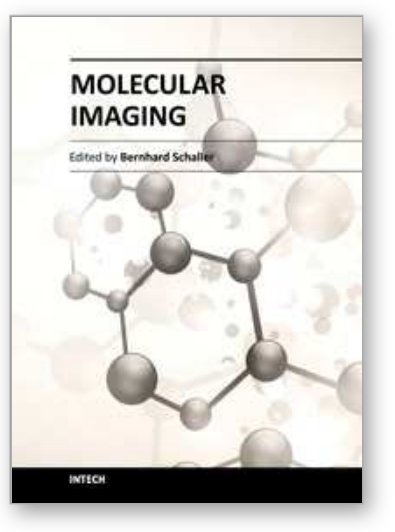

\author{
Molecular Imaging \\ Edited by Prof. Bernhard Schaller
}

ISBN 978-953-51-0359-2

Hard cover, 390 pages

Publisher InTech

Published online 16, March, 2012

Published in print edition March, 2012

The present book gives an exceptional overview of molecular imaging. Practical approach represents the red thread through the whole book, covering at the same time detailed background information that goes very deep into molecular as well as cellular level. Ideas how molecular imaging will develop in the near future present a special delicacy. This should be of special interest as the contributors are members of leading research groups from all over the world.

\title{
How to reference
}

In order to correctly reference this scholarly work, feel free to copy and paste the following:

Marcian E. Van Dort, Pedram Navid-Azarbaijani, Rajesh Ranga, Alnawaz Rehemtulla, Brian D Ross, Allan E David and Mahaveer S Bhojani (2012). PET and SPECT Imaging of Tumor Angiogenesis, Molecular Imaging, Prof. Bernhard Schaller (Ed.), ISBN: 978-953-51-0359-2, InTech, Available from:

http://www.intechopen.com/books/molecular-imaging/pet-and-spect-imaging-of-tumor-angiogenesis-

\section{INTECH}

open science | open minds

\section{InTech Europe}

University Campus STeP Ri

Slavka Krautzeka 83/A

51000 Rijeka, Croatia

Phone: +385 (51) 770447

Fax: +385 (51) 686166

www.intechopen.com

\section{InTech China}

Unit 405, Office Block, Hotel Equatorial Shanghai

No.65, Yan An Road (West), Shanghai, 200040, China 中国上海市延安西路65号上海国际贵都大饭店办公楼405单元

Phone: +86-21-62489820

Fax: +86-21-62489821 
(C) 2012 The Author(s). Licensee IntechOpen. This is an open access article distributed under the terms of the Creative Commons Attribution 3.0 License, which permits unrestricted use, distribution, and reproduction in any medium, provided the original work is properly cited. 